\title{
DERECHO Y POLÍTICAS AMBIENTALES EN LA COMUNIDAD DE MADRID
}

\section{(PRIMER SEMESTRE 2018)}

\author{
ANTONIO FORTES MARTÍN \\ Profesor titular de Derecho Administrativo \\ Universidad Carlos III de Madrid
}


Sumario: 1. Registro de explotaciones ganaderas y actividad apícola. 2. Creación de la Comisión Interdepartamental de Cambio Climático. 3. Regulación especial de la actividad piscícola. 4. Convocatoria de ayudas en materia de medio ambiente. 4.1. Ayudas para la adquisición de vehículos eficientes para uso de autotaxi y de vehículos comerciales ligeros eficientes, auxiliares y de servicios. 4.2. Ayudas para compatibilizar la actividad ganadera con la existencia de lobos, perros asilvestrados y buitres.

\section{REGISTRO DE EXPLOTACIONES GANADERAS Y ACTIVIDAD APÍCOLA}

El Decreto 146/2017, de 12 de diciembre, del Consejo de Gobierno de la Comunidad de Madrid crea y regula el registro de explotaciones ganaderas de la Comunidad de Madrid y establece la normativa reguladora de la actividad apícola.

Principalmente, y a partir de la regulación estatal (RD 209/2002, de 22 de febrero y RD 479/2004, de 26 de marzo), el objeto de la disposición no es otro que crear y regular, por una parte, el Registro de explotaciones ganaderas. A tal fin, quedan obligadas a la inscripción en el Registro todas las explotaciones ganaderas a partir de lo dispuesto en el artículo 3 del propio Decreto 146/2017. La voluntad de esta disposición es unificar en un único Registro todas las explotaciones ganaderas en el ámbito territorial de la Comunidad de Madrid. De este modo, el Registro de explotaciones ganaderas absorbe el Registro de explotaciones apícolas en el territorio de la Comunidad de Madrid que había sido creado por el Decreto 45/2015, de 30 de abril y que, en buena lógica, pasa a quedar derogado.

De otro lado, el Decreto 146/2017 dispone, en su Título III, la ordenación de la actividad apícola mediante el establecimiento de normas de ordenación sanitaria y zootécnica de las explotaciones apícolas, así como las condiciones de ubicación, asentamiento, y movimiento de colmenas.

Pese a su importante repercusión económica en el sector de la producción de la miel y otros productos, la apicultura, en tanto que actividad pecuaria, presenta también un indudable interés de cara al desarrollo rural y el equilibrio ecológico, constituyendo, en definitiva, la base para la conservación y la diversidad de las plantas que dependen de la polinización de la flora, cuyo efecto beneficioso provocado por la acción de las abejas está fuera de toda duda. 


\section{CREACIÓN DE LA COMISIÓN INTERDEPARTAMENTAL DE CAMBIO CLIMÁTICO}

El Decreto 6/2018, de 6 de febrero, del Consejo de Gobierno procede a la creación de la Comisión Interdepartamental de Cambio Climático de la Comunidad de Madrid. Casi un año después, la Comunidad de Madrid refuerza, desde un estricto punto de vista institucional, el interés organizativo por el cambio climático como quiera que el Decreto 36/2017, de 28 de marzo, del Consejo de Gobierno de la Comunidad de Madrid creó, previamente, el Comisionado del Gobierno de la Comunidad de Madrid para el Cambio Climático como nuevo órgano de la Consejería de Medio Ambiente, Administración Local y Ordenación del Territorio adscrito a la Viceconsejería de Medio Ambiente.

La razón que la Comunidad de Madrid esgrimió en su día para la creación del Comisionado fue la de ofrecer un papel más activo en materia de cambio climático con los consiguientes beneficios ambientales, económicos y sociales. $\mathrm{Y}$, a mayor abundamiento, "centralizar" o canalizar con esta figura las distintas políticas y medidas que se vienen desarrollando en la materia por parte de la diferentes Consejerías y Centros Directivos de la Comunidad de Madrid.

Sobre esa base organizativa, se crea también ahora la Comisión Interdepartamental de Cambio Climático como órgano colegiado para la propuesta de políticas y medidas de mitigación y adaptación al cambio climático, así como para la reducción de contaminantes atmosféricos. Como quiera que las materias de cambio climático y de calidad del aire presentan una evidente incidencia transversal y multisectorial que supera los aspectos estrictamente ambientales, de cara a una mayor eficacia y eficiencia, con la Comisión Interdepartamental se persigue involucrar de forma activa a los responsables de centros directivos y organismos dependientes de las distintas Consejerías del Gobierno regional. Se espera, de este modo, mejorar y potenciar la coordinación en la materia, haciendo, en última instancia, de las políticas climáticas y de mejora de la calidad del aire unas políticas de gobierno en la que las distintas Consejerías se sientan partícipes y responsables, todo ello sin perjuicio de las competencias concretas que de forma expresa le 
corresponden y tiene atribuidas la Consejería de Medio Ambiente, Administración Local y Ordenación del territorio.

Finalmente, puede apuntarse, a partir de lo dispuesto en el artículo 3 del Decreto 6/2018, que la Comisión Interdepartamental tiene por finalidad identificar e integrar, desde la perspectiva de sus respectivas políticas sectoriales, las medidas concretas que contribuyan a cumplir los objetivos establecidos en la estrategia de calidad del aire y cambio climático.

\section{REGULACIÓN ESPECIAL DE LA ACTIVIDAD PISCÍCOLA}

Dentro del capítulo relativo a la regulación de la actividad piscícola, corresponde hacer un breve análisis de la Orden 270/2018, de 12 de febrero, de la Consejería de Medio Ambiente, Administración Local y Ordenación del Territorio, sobre establecimiento de vedas y regulación especial de la actividad piscícola en los ríos, arroyos y embalses de la Comunidad de Madrid, para el ejercicio de 2018.

La conservación y regulación de las poblaciones piscícolas que habitan en las masas de agua de la Comunidad de Madrid precisa de su ordenado aprovechamiento de conformidad con lo dispuesto en el artículo 62.1 de la Ley 42/2007, de 13 de diciembre, del patrimonio natural y de la biodiversidad y del artículo 41.d) de la Ley 1/83, de 13 de diciembre, de Gobierno y Administración de la Comunidad de Madrid. Y como quiera que, a partir de las previsiones estatutarias y en virtud del RD 1703/84, de 1 de agosto, sobre el traspaso de funciones y servicios del Estado en materia de conservación de la naturaleza, la Comunidad de Madrid tiene atribuidas las funciones de protección, conservación, fomento, y ordenado aprovechamiento de la riqueza piscícola continental y la aplicación de las medidas conducentes a la consecución de estos fines, así como la vigilancia y el control de las aguas continentales en todo lo que tiene que ver con la riqueza piscícola, la Orden objeto de estudio contempla la regulación, para el año 2018 , del ejercicio de la pesca deportiva en el ámbito de las aguas de la Comunidad de Madrid.

La disposición no establece una regulación particularmente destacada, por novedosa, de la que se viene aprobando, para cada ejercicio, en años 
precedentes donde, una vez más, el objeto de la Orden es establecer las limitaciones y épocas hábiles para el ejercicio de la pesca en el ámbito de las aguas de la Comunidad de Madrid en el curso 2018. Más bien, se recrea una ordenación administrativa típica o al uso detallando pormenorizadamente en sus veintiocho artículos i) los permisos de pesca —en tanto que autorización administrativa que acredita el derecho a ejercitar la pesca en un tramo acotado en una fecha determinada ( $y$, por tanto, distintos de la licencia de pesca que debe tener el interesado previamente)_. A mayor abundamiento, la utilización de esos permisos de pesca determina la clasificación a la que quedan sujetos los pescadores en los términos del artículo 7 de la Orden, a saber, Pescadores de sociedad colaboradora, Pescadores ribereños, y otros pescadores; ii) las especies objeto de pesca deportiva en el ámbito territorial de la Comunidad de Madrid (que son las relacionadas en el artículo 9 y anexo I de la Orden) mediante las artes y métodos legales (concretados en los artículos 22 y 23 de la Orden, con especificación de las artes prohibidas en todo el ámbito de la Comunidad de Madrid en el anexo IV de la Orden) en los tramos autorizados a tal fin (donde se diferencian en este punto tramos libres, tramos acotados, tramos de pesca controlada, tramos experimentales de pesca, tramos vedados -art. 13-, y finalmente un régimen especial de los llamados tramos de captura y suelta -art. 16-); iii) el régimen especial de la pesca en aguas privadas (art. 17 de la Orden) y el de las zonas piscícolas comprendidas en espacios naturales protegidos y espacios con Planes de Ordenación de los Recursos Naturales o Planes Rectores de Uso y Gestión (art. 18 de la Orden); iv) las dimensiones mínimas de las especies objeto de pesca, los cupos máximos (ambos extremos también detallados en el citado anexo l y, respectivamente, en los arts. 10 y 11 de la Orden), así como la comercialización y el transporte de las especies objeto de pesca (art. 26 de la Orden); y, finalmente, y entre otros extremos, v) el régimen de la pesca con fines científicos (artículo 27 de la Orden); y vi) el horario de pesca durante cada jornada que, de conformidad con el artículo 21, se establece desde una hora antes de la salida del sol hasta una hora después de su puesta. Cabe, no obstante, tener en cuenta que la Consejería de Medio Ambiente y Ordenación del Territorio se encuentra facultada (art. 1.2) para establecer normas de carácter extraordinario cuando sea estrictamente necesario para la 
conservación de alguna especie de la fauna acuícola continental o bien cuando lo aconsejen los resultados de estudios hidrobiológicos o por cualquier otra causa que por razones de urgencia sea preciso de cara al establecimiento de dicha normativa extraordinaria.

\section{CONVOCATORIA DE AYUDAS EN MATERIA DE MEDIO AMBIENTE}

\subsection{Ayudas para la adquisición de vehículos eficientes para uso de autotaxi y de vehículos comerciales ligeros eficientes, auxiliares y de servicios}

La Orden 323/2018, de 13 de febrero, de la Consejería de Medio Ambiente, Administración Local y Ordenación del Territorio modifica las bases reguladoras para la concesión de las ayudas para la adquisición de vehículos eficientes para uso de autotaxi dispuestas por la Orden 2157/2013, de 23 de septiembre, de la Consejería de Medio Ambiente y Ordenación del Territorio. Asimismo, la Orden 322/2018, de 13 de febrero, de la Consejería de Medio Ambiente, Administración Local y Ordenación del Territorio modifica la Orden 3222/2014, de 22 de diciembre, por la que se establecen las bases reguladoras para la concesión de las ayudas para la adquisición de vehículos comerciales ligeros eficientes, auxiliares y de servicios.

El engarce entre la Orden 323/2018 y la Orden 2157/2013 así como entre la Orden 322/2018 y la Orden 3222/2014 nos obliga a tener presente, tal y como hemos abordado en alguna otra crónica ambiental anterior sobre este mismo particular, justamente el alcance, tanto de la Orden 2157/2013, como de la Orden 3222/2014. Ambas disposiciones apuestan por el estímulo para acelerar la renovación de la flota actual de autotaxis y de vehículos comerciales ligeros eficientes, auxiliares y de servicios en la Comunidad de Madrid a través de la incorporación de modelos de alta eficiencia energética, con menor consumo de combustible, y menos emisiones de dióxido de nitrógeno y de óxidos de nitrógeno. Y, desde entonces, y hasta el momento actual, la línea de ayudas concedida al amparo de la Orden 2157/2013 ha permitido la renovación de 1.663 vehículos autotaxi; mientras que, en el caso de la Orden 3222/2014, ha posibilitado la renovación de 382 furgonetas o furgones en el claro propósito de 
potenciar una disminución de las emisiones de contaminantes atmosféricos de todos estos vehículos por su sustitución por otros vehículos con cero o bajas emisiones de contaminantes atmosféricos.

Al amparo del Plan Nacional de Calidad del Aire y Protección de la Atmósfera 2013-2016 (Plan Aire), la Dirección General de Tráfico, mediante Resolución de 13 de abril de 2016, posteriormente modificada por Resolución de 2 de enero de 2017, ha procedido a clasificar el parque de los vehículos matriculados en función de sus emisiones. Y a resultas de esto mismo, la Orden 323/2018 y la Orden 322/2018 proceden a modificar los tramos establecidos por la Orden 2157/2013, de 23 de septiembre y por la Orden 3222/2014, de 22 de diciembre, respectivamente, para baremar la cuantía de las ayudas en función del etiquetado de la Dirección General de Tráfico. Así las cosas, la ayuda prevista para la adquisición de vehículos autotaxi por la Orden 2157/2013, de 23 de septiembre, tras la modificación operada por la Orden $323 / 2018$, se va a prestar por la adquisición de vehículos cero emisiones (Tramo I con una ayuda de 8.000 euros/vehículo); vehículos ECO (Tramo II con una ayuda de 2.000 euros/vehículo); o vehículos pertenecientes a la categoría Eurotaxis adaptados para personas con movilidad reducida y clasificados como Cero emisiones, ECO o C (Tramo III con una ayuda de 3.000 euros/vehículo o de 2.000 euros/vehículo, respectivamente), todos ellos de acuerdo con el Anexo VIII de la Resolución de 13 de abril de 2016 de la Dirección General de Tráfico. Mientras que, en el caso de la Orden 3222/2014, de 22 de diciembre, tras la modificación operada por la Orden 322/2018, la ayuda se va a prestar por la adquisición de vehículos correspondientes a la categoría N1 (con masa máxima no superior a 3.5 toneladas) especialmente diseñados y fabricados para el reparto comercial auxiliar y de servicios clasificados como Cero emisiones (Tramo I con una ayuda de 8.000 euros/vehículo) o ECO (Tramo II con una ayuda de 3.000 euros/vehículo); y de vehículos de la categoría N2 (con masa máxima superior a 3.5 toneladas e inferior a 12) especialmente diseñados y fabricados para el reparto comercial auxiliar y de servicios clasificados como Cero emisiones (Tramo I con una ayuda de 10.000 euros/vehículo), ECO (Tramo II con una ayuda de 4.000 euros/vehículo) o C (Tramo III con una ayuda de 2.000 euros/vehículo), todos ellos de acuerdo con 
las previsiones del Anexo VIII de la Resolución de 13 de abril de 2016 de la Dirección General de Tráfico.

\subsection{Ayudas para compatibilizar la actividad ganadera con la existencia de lobos, perros asilvestrados y buitres}

La Orden 435/2018, de 22 de febrero, de la Consejería de Medio Ambiente, Administración Local y Ordenación del Territorio de la Comunidad de Madrid convoca para el año 2018 las ayudas destinadas a compatibilizar la actividad ganadera con la existencia de poblaciones de lobos, perros asilvestrados, y buitres en la Comunidad de Madrid.

La convocatoria y ulterior concesión de estas ayudas encuentra acomodo en la Disposición Adicional $2^{a}$ de la Ley $2 / 91$, de 14 de febrero, para la protección y regulación de la fauna y la flora silvestres de la Comunidad de Madrid. La citada Disposición Adicional prevé la concesión de ayudas a los titulares de terrenos o derechos reales para la realización de programas de conservación cuando los mencionados terrenos se encuentren ubicados en espacios protegidos, o bien para llevar a cabo planes de recuperación o manejo de especies o de conservación y protección de hábitats previstos en la Ley 2/91.

La Orden ahora comentada contempla un régimen de ayudas, de concesión directa, que se orienta a paliar los daños económicos ocasionados a los ganaderos por la pérdida de su producto en los eventuales ataques que puedan provocar los lobos, perros salvajes y buitres a sus animales de producción o cabezas de ganado. En este sentido, puede ser beneficiario de las ayudas cualquier titular de explotaciones ganaderas de animales de especies bovina, ovina, caprina, y equina que se encuentren localizadas dentro de la Comunidad de Madrid. En todo caso, los eventuales beneficiarios deben cumplir con la legislación vigente en materia de identificación animal, programas nacionales de erradicación de enfermedades, así como otros programas obligatorios en materia de producción, sanidad, y bienestar animal.

Por último, las ayudas se encuentran supeditadas a la producción de un ataque por parte de un lobo, perro salvaje o buitre. A tal fin, y acaecido un siniestro, el ganadero tiene la obligación de comunicarlo de forma inmediata, y en el plazo máximo de 48 horas, a la Dirección General de Medio Ambiente y al Cuerpo de 
Agentes Forestales. Esta obligación no sólo entraña una comunicación del evento sino, además, la puesta a disposición de las autoridades de los cadáveres de las reses o cualquier otra evidencia que permita dictaminar que el ataque merece la reparación económica correspondiente. 